\title{
Systemic treatment for hereditary cancers: a 2012 update
}

Evgeny N Imyanitov ${ }^{1,2,3^{*}}$ and Tomasz Byrski ${ }^{4,5}$

\begin{abstract}
The history of specific therapy for hereditary tumors dates back to mid 1980s and involves a number of reports demonstrating regression of familial colon polyps upon administration of sulindac. Virtually no clinical studies on other hereditary cancer types were available until the year 2009, when Byrski et al. presented the data on unprecedented sensitivity of BRCA1-associated breast malignancies to cisplatin. This breakthrough has revived interest to the treatment of cancer in germ-line mutation carriers. Recent trials and clinical observations have confirmed the efficacy of platinating agents and PARP inhibitors in BRCA1/2-driven breast, ovarian and pancreatic carcinomas. Pegylated liposomal doxorubicin may be considered as a promising treatment option for BRCA1/2related ovarian cancer after the failure of platinum-containing therapy. Several novel drugs have been recently introduced in the management of rare familial tumor syndromes. Vandetanib, a low-molecular weight RET kinase inhibitor, demonstrated substantial efficacy in the treatment of hereditary and sporadic medullary thyroid cancer. Vismodegib, an inhibitor of SMO oncoprotein, caused regression of basal-cell carcinomas in patients with Gorlin syndrome. Down-regulation of mTOR kinase by everolimus has been successfully used for the therapy of subependymal giant-cell astrocytomas in patients with tuberous sclerosis. The achievements in the prevention, diagnostics and treatment of hereditary cancers may serve as an excellent example of triumph of translational medicine.
\end{abstract}

\section{Introduction}

$1-5 \%$ of human cancers develop due to known germ-line defects. Virtually all major hereditary tumor types differ from their sporadic counterparts with respect to the underlying biological mechanisms, and thus may be considered as a somewhat distinct disease entity. First reports on specific therapy of familial tumors date back to mid 1980s [1]. It is getting increasingly apparent that cancers arising in mutation carriers often demonstrate peculiar spectrum of drug sensitivity [2]. Here we review recent advances and controversies in this field.

\section{Breast cancer}

There are over 10 genes causing hereditary forms of breast cancer (BC), however only BRCA1- and BRCA2-related disease has been studied with sufficient level of comprehension. It is commonly stated that BRCA-driven malignancies are triggered by somatic inactivation of the remaining

\footnotetext{
*Correspondence: evgeny@imyanitov.spb.ru

'Laboratory of Molecular Oncology, NN Petrov Institute of Oncology,

St.-Petersburg 197758, Russia

2Department of Medical Genetics, St-Petersburg Pediatric Medical University, St-Petersburg 194100, Russia

Full list of author information is available at the end of the article
}

(wild-type) BRCA allele, thus providing an unique opportunity for a tumor-specific therapy. Indeed, while normal tissues of BRCA mutation carriers retain a non-altered copy of the gene, the transformed cells are characterized by complete loss of BRCA function. Absence of the BRCA1 or BRCA2 compromises DNA repair and increases sensitivity of the cell to particular DNA damaging agents [2,3].

Clinical studies on breast cancer demonstrated an unique sensitivity of BRCA1-accociated tumors to cisplatin [4]. The available literature describes 15 BRCA1 carriers treated by neoadjuvant cisplatin for BC, and 13 (87\%) of them showed pathological complete response (pCR) [5-8]. First data on the use of cisplatin in metastatic setting have been published recently. Byrski et al. [9] observed objective responses in 16/20 (80\%) patients, some of them heavily pretreated. Moiseyenko et al. [10] described a patient with BRCA1-related $\mathrm{BC}$ whose tumor did not respond to the first-line anthracyline-taxane therapy, but markedly regressed after administration of cisplatin. An experimental PARP1 inhibitor, olaparib, has also shown very encouraging results in both BRCA1- and BRCA2-driven BC, however its regulatory approval may take longer than initially expected [11].

\section{Biomed Central}

(c) 2013 Imyanitov and Byrski; licensee BioMed Central Ltd. This is an Open Access article distributed under the terms of the Creative Commons Attribution License (http://creativecommons.org/licenses/by/2.0), which permits unrestricted use, distribution, and reproduction in any medium, provided the original work is properly cited. 
Taxanes exert antitumor action via BRCA1-mediated apoptosis, therefore BRCA1-deficiency may mediate resistance to docetaxel or paclitaxel. Two systematic studies on $\mathrm{BC}$ provided strong support to this hypothesis. Kriege et al. [12] investigated taxane monotherapy for the treatment of metastatic BC disease, and described lower response rate and shorter progression-free survival in BRCA1-heterozygous patients as compared to BRCA2related and sporadic cases. Byrski et al. [6] reported only $2 / 25(8 \%)$ pathological complete responses in the BRCA1 patients treated by anthracycline-taxane (AT) combinations, while presumably less potent taxane-free anthracycline-containing regimens yielded 22\% (11/51) pCRs. However, Arun et al. [13] recently presented the experience of neoadjuvant $\mathrm{BC}$ treatment in the $\mathrm{MD}$ Anderson Cancer Center, where BRCA1 carriers demonstrated high $\mathrm{pCR}$ rates for anthracycline-containing regimens both with and without taxanes (21/46 (46\%) and $4 / 9$ (44\%), respectively). Entirely different outcomes of the AT therapy in the studies of Byrski et al. [6] and Arun et al. [13] deserve particular attention. It is essential to comment that while Byrski et al. [6] used the combination of doxorubicin and docetaxel for all described patients, run et al. [13] utilized a number of AT regimens; for example, some patients received distinct anthracycline (epirubicin) and/or taxane (paclitaxel) and/or were treated with the addition of 5-fluorouracil and/or cyclophosphamide.

A number of issues may be considered while designing the $\mathrm{BC}$ studies for the near future. The list of known BC genes is rapidly expanding, with the CHEK2 being apparently the most frequent cause of hereditary $\mathrm{BC}$ after BRCA1 and BRCA2. Drug response of CHEK2-related $\mathrm{BCs}$ has not been evaluated yet, neither in laboratory experiments nor in the patients [2]. Furthermore, the whole idea of selective chemosensitivity of BRCA-related BC is based on the "two-hit" hypothesis; however, some of the recent data indicate, that $\mathrm{BCs}$ arising in BRCA1 mutation carriers do not necessarily display the loss of the remaining allele, and haploinsufficiency of heterozygous BRCA1 cells may at least in some instances contribute to tumorigenesis [14-16]. It is of interest whether the actual somatic status of BRCA genes indeed influences the tumor response to the treatment. Most importantly, even highly BRCAselective drugs, like cisplatin or PARP1 inhibitors, offer only a temporary tumor regression in the metastatic BC patients. It is hoped that intelligent combining of BRCAspecific compounds may offer significantly better outcomes [17]. The reported instances of cure of BRCA-mutated stage IV BCs by high-dose chemotherapy may deserve particular attention in this respect $[18,19]$.

\section{Ovarian cancer}

Approximately $15 \%$ of ovarian cancers (OCs) arise due to inherited BRCA1 or BRCA2 mutation. In addition, a significant portion of serous OCs demonstrate somatic inactivation of BRCA1/2 genes and therefore have similar biological properties [20]. BRCA deficiency explains sensitivity of $\mathrm{OC}$ to platinum-containing therapy and PARP1 inhibitors, which appears to be somewhat more pronounced in hereditary versus sporadic cases [21-23]. Prolonged drug treatment usually leads to the tumor resistance, which at least in some instances is attributed to the restoration of the BRCA gene function through the gain of second mutation [24].

The most noticeable achievement of the recent months is a convincing demonstration of high efficacy of pegylated liposomal doxorubicin (PLD) in BRCA-related ovarian cancer. PLD is an advanced formulation of doxorubicin, which is characterized by more favorable pharmacokinetic, pharmacodynamic and safety profiles as compared to conventional anthracyclines. PLD is included in the spectrum of drugs, which may be used for the treatment of ovarian cancer after failure of platinum-based therapy. Safra et al. [25] retrospectively compared the performance of $2^{\text {nd }}$ - and $3^{\text {rd }}$-line PLD in proven BRCA1/2-carriers versus presumably non-hereditary $\mathrm{OC}$ patients; the objective response rates were $68 \%$ versus $49 \%$, and the median time to treatment failure was 15.8 months versus 8.1 months. Adams et al. [26] considered PLD users with an average 2.7 prior chemotherapeutic regimens (range: 0-6), and also observed increased frequency of tumor responses (57\% versus $20 \%$ ) and prolonged progression-free survival (27.1 weeks versus 17.0 weeks) in BRCA mutation carriers. Kaye et al. [27] performed randomized comparison of PLD and olaparib in heavily pretreated BRCA-heterozygous OC patients; PLD arm demonstrated objective response rate of $18 \%$ and progression survival of 7.1 months, that was similar to the efficacy of the PARP1 inhibition. In contrast to PLD, topotecan, being also a standard therapeutic option for the previously treated ovarian cancer, showed null clinical benefit rate in BRCA mutation carriers [28].

A high-throughput pharmaceutical screen on BRCA2deficient mouse mammary tumor cells pointed at potential efficacy of a well-known alkylating cytotoxic drug, melphalan [29]. In accordance with laboratory findings, Osher et al. [30] reported a patient with metastatic ovarian cancer, who received melphalan during 1 year in 1980 s and remains disease-free for over 25 years.

\section{Pancreatic cancer}

Pancreatic cancer (PC) is known for its resistance to virtually all available cytotoxic agents. However, $5 \%$ to $10 \%$ of PCs are caused by germ-line mutations in BRCA1, BRCA2 or PALB2 genes, and this subset of tumors may demonstrate significant sensitivity to DNA damaging agents and PARP1 inhibitors. There is a number of case observations supporting this assumption [31-33]. Two systematic studies on this issue have been reported in 
recent months. Lowery et al. [34] described 4 patients with advanced BRCA-related PC receiving PARP inhibitor alone or in combination with chemotherapy; 3 tumors responded to the treatment and 1 demonstrated stabilization of the disease. 6 patients from the same study underwent platinum-containing first-line therapy, and 5 of them showed response to the treatment. Faluyi et al. [35] described 11 BRCA-driven cases of metastatic PC; 2 complete and 3 partial responses were documented in 5 patients receiving platinum-containing drug combinations, while only 1 out of 6 PCs responded to gemcitabine.

\section{Colorectal cancer}

Almost all colorectal cancers (CRCs), which arise in carriers of DNA mismatch repair (MMR) gene mutations, show instability of microsatellite repeats (MSI). MSI is also characteristic for a subset of sporadic CRCs. Both hereditary and sporadic MSI+ CRCs demonstrate reasonably favorable prognosis, probably due to immunogenicity of microsatellite unstable tumors. While familial CRCs are usually early-onset, sporadic MSI+ tumors are typical for elderly individuals. The latter category of MSI + cancers is also characterized by the presence of BRAF mutations [36]. MSI test is technically easier that the detection of germ-line defects in MMR genes, therefore virtually all available studies consider MSI status without referring to inherited mutations in the MLH1, MSH2 or other candidates. Recently Sinicrope et al. [37] attempted to discriminate hereditary versus sporadic MSI+ CRCs based on patients age (younger versus older than 55 years) and, wherever possible, somatic BRAF status. This analysis led to suggestion that presumably hereditary stage III MSI+ CRCs do benefit from 5-fluorouracil-based therapy, while presumably sporadic ones do not.

There is an emerging class of targeted drugs, whose action is based on stimulation of local antitumor immune response [38,39]. They deserve to be considered for the future trials on MSI+ colorectal carcinomas, given a pronounced immunogenicity of this CRC subset.

\section{Medullary thyroid cancer}

Hereditary forms of medullary thyroid cancer (MTC) develop due to inherited mutation in the RET oncogene and demonstrate pronounced sensitivity to the RET tyrosine kinase inhibitor, vandetanib [40]. Vandetanib studies were recently expanded to non-selected MTC, given frequent somatic RET alterations in sporadic tumors of this type [41]. The progression-free survival rate at 6 months was $83 \%$ for vandetanib versus $63 \%$ for placebo. Most of included patients had either confirmed RET mutation (hereditary or sporadic) or unknown RET status, and the former tended to fare better than the latter. This study led to the approval of the drug; interestingly, the European Medicines Agency recommends to evaluate RET mutation status while considering vandetanib therapy [http://www.ema.europa.eu/docs/en_GB/ document_library/EPAR_-_Product_Information/human/ 002315/WC500123555.pdf], while the Food and Drug Administration states in the drug label that there is no evidence of a relationship between RET mutations and efficacy of this compound [http://www.accessdata.fda.gov/ drugsatfda_docs/label/2011/022405s001lbl.pdf].

\section{Basal-cell nevus syndrome}

Basal-cell nevus (Gorlin) syndrome is a rare hereditary disorder which is caused by mutation in the PTCH1 gene. PTCH1 inactivation abolishes its negative regulation of the SMO oncogene and thus initiates the growth of multiple basal-cell carcinomas. Clinical administration of a specific SMO inhibitor, vismodegib, prevented the appearance of new malignancies and resulted in the regression of existing neoplasms. None of the lesions progressed during the treatment, however the systemic tumor disease quickly relapsed after discontinuation of the therapy [42].

\section{Astrocytomas in tuberous sclerosis}

Tuberous sclerosis is caused by germ-line mutations in TSC1 or TSC 2 suppressor genes. Disruption of TSC1 or TSC2 leads to uncontrolled activation of mTOR kinase, and, consequently, to neoplastic growth. Tumors arising in patients with tuberous sclerosis are usually benign, however some of the neoplasms, especially if located in the brain, may cause severe disability and death. Recent development of specific mTOR inhibitors provided novel opportunities for the management of tuberous sclerosis. In particular, promising results have been achieved with everolimus: administration of this drug to the patients with serial subependymal giant-cell astrocytomas led to the marked tumor reduction in 21 (75\%) of 28 enrolled patients [43].

\section{Conclusions and perspectives}

Recent studies have convincingly demonstrated that hereditary and sporadic tumors may indeed require distinct treatment approaches. Ongoing revolution in technologies of DNA analysis, particularly the invention of nextgeneration sequencing, allows to expect that dozens of new familial cancer genes will be identified in the near future. Furthermore, dramatic increase of velocity and cost-efficiency of germ-line mutation testing provides the hope that virtually every cancer patient will soon be undergoing genetic examination right at the time of tumor diagnosis [44]. Advances in the management of hereditary cancer syndromes may serve as an excellent example of the power of translational medicine. 


\section{Abbreviations}

AT: Anthracycline-taxane combinations; BC: Breast cancer; CRC: Colorectal cancer; OC: Ovarian cancer; pCR: Pathological complete response; MMR: DNA mismatch repair; MSI: Microsatellite instability; MTC: Medullary thyroid cancer; PC: Pancreatic cancer; PLD: Pegylated liposomal doxorubicin.

\section{Competing interests}

The authors declare that they have no competing interests.

\section{Authors' contributions}

ENI and TB, drafted the manuscript. Both authors read and approved the final manuscript.

\section{Acknowledgements}

This work has been supported by the Russian Federation for Basic Research (grant 11-04-00227), Federal Agency for Science and Innovations (contract 14.512.11.0041), the Commission of the European Communities (grant PITN-GA-2009-238132) and the Government of Moscow (grant 15/13).

\section{Author details}

'Laboratory of Molecular Oncology, NN Petrov Institute of Oncology, St.-Petersburg 197758, Russia. ${ }^{2}$ Department of Medical Genetics, St-Petersburg Pediatric Medical University, St-Petersburg 194100, Russia. ${ }^{3}$ Department of Oncology, II Mechnikov North-Western Medical University, St.-Petersburg 191015, Russia. ${ }^{4}$ International Hereditary Cancer Center, Pomeranian Medical University, Szczecin 70-111, Poland. ${ }^{5}$ Clinic of Oncology, Pomeranian Medical University, Szczecin 70-111, Poland.

Received: 25 October 2012 Accepted: 13 March 2013

Published: 1 April 2013

\section{References}

1. Waddell WR, Loughry RW: Sulindac for polyposis of the colon. J Surg Oncol 1983, 24:83-87.

2. Imyanitov EN, Moiseyenko VM: Drug therapy for hereditary cancers. Hered Cancer Clin Pract 2011, 9:5.

3. Narod SA: BRCA mutations in the management of breast cancer: the state of the art. Nat Rev Clin Oncol 2010, 7:702-707.

4. Imyanitov EN: Breast cancer therapy for BRCA1 carriers: moving towards platinum standard? Hered Cancer Clin Pract 2009, 7:8.

5. Byrski T, Huzarski T, Dent R, Gronwald J, Zuziak D, Cybulski C, Kladny J, Gorski B, Lubinski J, Narod SA: Response to neoadjuvant therapy with cisplatin in BRCA1-positive breast cancer patients. Breast Cancer Res Treat 2009, 115:359-363.

6. Byrski T, Gronwald J, Huzarski T, Grzybowska E, Budryk M, Stawicka M, Mierzwa T, Szwiec M, Wisniowski R, Siolek M, Dent R, Lubinski J, Narod S: Pathologic complete response rates in young women with BRCA1positive breast cancers after neoadjuvant chemotherapy. J Clin Oncol 2010, 28:375-379.

7. Silver DP, Richardson AL, Eklund AC, Wang ZC, Szallasi Z, Li Q, Juul N, Leong CO, Calogrias D, Buraimoh A, Fatima A, Gelman RS, Ryan PD, Tung NM, De Nicolo A, Ganesan S, Miron A, Colin C, Sgroi DC, Ellisen LW, Winer EP, Garber JE: Efficacy of neoadjuvant Cisplatin in triple-negative breast cancer. J Clin Oncol 2010, 28:1145-1153.

8. Kołacińska A, Chałubińska J, Błasińska-Morawiec M, Dowgier-Witczak ! Fendler W, Kordek R, Morawiec Z: Pathological complete response in younger and older breast cancer patients. Arch Med Sci 2012, 8:310-315.

9. Byrski T, Dent R, Blecharz P, Foszczynska-Kloda M, Gronwald J, Huzarski T, Cybulski C, Marczyk E, Chrzan R, Eisen A, Lubinski J, Narod S: Results of a phase II openlabel, non randomized trial of cisplatin chemotherapy in patients with BRCA1-positive metastatic breast cancer. Breast Cancer Res 2012, 14:R110.

10. Moiseyenko VM, Protsenko SA, Brezhnev NV, Maximov SY, Gershveld ED, Hudyakova MA, Lobeiko OS, Gergova MM, Krzhivitskiy PI, Semionov II, Matsko DE, lyevleva AG, Sokolenko AP, Sherina NY, Kuligina ES, Suspitsin EN, Togo AV, Imyanitov EN: High sensitivity of BRCA1-associated tumors to cisplatin monotherapy: report of two cases. Cancer Genet Cytogenet 2010, 197:91-94

11. Domchek SM, Mitchell G, Lindeman GJ, Tung NM, Balmaña J, Isakoff SJ, Schmutzler R, Audeh MW, Loman N, Scott C, Friedlander M, Kaufman B, Garber JE, Tutt A, Robson ME: Challenges to the development of new agents for molecularly defined patient subsets: lessons from BRCA1/2-associated breast cancer. J Clin Oncol 2011, 29:4224-4226.
12. Kriege $M$, Jager $A$, Hooning MJ, Huijskens $E$, Blom J, van Deurzen $C H$, Bontenbal M, Collee JM, Menke-Pluijmers MB, Martens JW, Seynaeve C: The efficacy of taxane chemotherapy for metastatic breast cancer in BRCA1 and BRCA2 mutation carriers. Cancer 2012, 118:899-907.

13. Arun B, Bayraktar S, Liu DD, Gutierrez Barrera AM, Atchley D, Pusztai L, Litton JK, Valero V, Meric-Bernstam F, Hortobagyi GN, Albarracin C: Response to neoadjuvant systemic therapy for breast cancer in BRCA mutation carriers and noncarriers: a single-institution experience. J Clin Oncol 2011, 29:3739-3746.

14. Meric-Bernstam F: Heterogenic loss of BRCA in breast cancer: the "two-hit" hypothesis takes a hit. Ann Surg Oncol 2007, 14:2428-2429.

15. Beristain E, Guerra I, Vidaurrazaga N, Burgos-Bretones J, Tejada MI: LOH analysis should not be used as a tool to assess whether UVs of BRCA1/2 are pathogenic or not. Fam Cancer 2010, 9:289-290.

16. Konishi H, Mohseni M, Tamaki A, Garay JP, Croessmann S, Karnan S, Ota A, Wong HY, Konishi Y, Karakas B, Tahir K, Abukhdeir AM, Gustin JP, Cidado J, Wang GM, Cosgrove D, Cochran R, Jelovac D, Higgins MJ, Arena S, Hawkins L, Lauring J, Gross AL, Heaphy CM, Hosokawa Y, Gabrielson E, Meeker AK, Visvanathan K, Argani P, Bachman KE, Park BH: Mutation of a single allele of the cancer susceptibility gene BRCA1 leads to genomic instability in human breast epithelial cells. Proc Natl Acad Sci USA 2011, 108:17773-17778.

17. Somlo G, Sparano JA, Cigler T, Fleming GF, Luu TH, Hurria A, Mortimer JE, Frankel PH, Chew HK, Nanda R, Ma CX, Chen AP, Garcia A, Vahdat LT, Gandara DR, Weitzel JN: ABT-888 (veliparib) in combination with carboplatin in patients with stage IV BRCA-associated breast cancer. A California Cancer Consortium Trial. J Clin Oncol 2012, 30(Suppl):abstr 1010

18. Huang F, Kushner YB, Langleben A, Foulkes WD, Medscape: Eleven years disease-free: role of chemotherapy in metastatic BRCA2-related breast cancer. Nat Rev Clin Oncol 2009, 6:488-492.

19. Vollebergh MA, Nederlof PM, Wessels LF, Schmidt MK, Joosse SA, Van Beers E, Froklage F, Holtkamp M, Schrama JG, Wesseling J, Hauptmann M, De Bruin M, Rodenhuis S, Linn SC: Predicting response to alkylating chemotherapy in breast cancer patients using array comparative genomic hybridization. Cancer Res 2009, 69(Suppl 1):abstr 6050.

20. Hennessy BT, Timms KM, Carey MS, Gutin A, Meyer LA, Flake DD 2nd, Abkevich V, Potter J, Pruss D, Glenn P, Li Y, Li J, Gonzalez-Angulo AM, McCune KS, Markman M, Broaddus RR, Lanchbury JS, Lu KH, Mills GB: Somatic mutations in BRCA1 and BRCA2 could expand the number of patients that benefit from poly (ADP ribose) polymerase inhibitors in ovarian cancer. J Clin Oncol 2010, 28:3570-3576.

21. Gelmon KA, Tischkowitz M, Mackay H, Swenerton K, Robidoux A, Tonkin K, Hirte H, Huntsman D, Clemons M, Gilks B, Yerushalmi R, Macpherson E, Carmichael J, Oza A: Olaparib in patients with recurrent high-grade serous or poorly differentiated ovarian carcinoma or triple-negative breast cancer: a phase 2, multicentre, open-label, non-randomised study. Lancet Oncol 2011, 12:852-861.

22. Vencken PM, Kriege M, Hoogwerf D, Beugelink S, van der Burg ME, Hooning MJ, Berns EM, Jager A, Collée M, Burger CW, Seynaeve C: Chemosensitivity and outcome of BRCA1- and BRCA2-associated ovarian cancer patients after first-line chemotherapy compared with sporadic ovarian cancer patients. Ann Oncol 2011, 22:1346-1352.

23. Alsop K, Fereday S, Meldrum C, Defazio A, Emmanuel C, George J, Dobrovic A, Birrer MJ, Webb PM, Stewart C, Friedlander M, Fox S, Bowtell D, Mitchell $\mathrm{G}$ : BRCA mutation frequency and patterns of treatment response in BRCA mutation-positive women with ovarian cancer: a report from the Australian ovarian cancer study group. J Clin Oncol 2012, 30:2654-2663.

24. Norquist B, Wurz KA, Pennil CC, Garcia R, Gross J, Sakai W, Karlan BY, Taniguchi T, Swisher EM: Secondary somatic mutations restoring BRCA1/2 predict chemotherapy resistance in hereditary ovarian carcinomas. J Clin Oncol 2011, 29:3008-3015.

25. Safra $T$, Borgato $L$, Nicoletto MO, Rolnitzky $L$, Pelles-Avraham S, Geva R, Donach ME, Curtin J, Novetsky A, Grenader T, Lai WC, Gabizon A, Boyd L, Muggia F: BRCA mutation status and determinant of outcome in women with recurrent epithelial ovarian cancer treated with pegylated liposomal doxorubicin. Mol Cancer Ther 2011, 10:2000-2007.

26. Adams SF, Marsh EB, Elmasri W, Halberstadt S, Vandecker S, Sammel MD, Bradbury AR, Daly M, Karlan B, Rubin SC: A high response rate to liposomal doxorubicin is seen among women with BRCA mutations treated for recurrent epithelial ovarian cancer. Gynecol Oncol 2011, 123:486-491. 
27. Kaye SB, Lubinski J, Matulonis U, Ang JE, Gourley C, Karlan BY, Amnon A, Bell-McGuinn KM, Chen LM, Friedlander M, Safra T, Vergote I, Wickens M, Lowe ES, Carmichael J, Kaufman B: Phase II, open-label, randomized, multicenter study comparing the efficacy and safety of olaparib, a poly (ADP-ribose) polymerase inhibitor, and pegylated liposomal doxorubicin in patients with BRCA1 or BRCA2 mutations and recurrent ovarian cancer. J Clin Oncol 2012, 30:372-379.

28. Hyman DM, Zhou Q, Arnold AG, Grisham RN, lasonos A, Kauff ND, Spriggs D: Topotecan in patients with BRCA-associated and sporadic platinum-resistant ovarian, fallopian tube, and primary peritoneal cancers. Gynecol Oncol 2011, 123:196-199.

29. Evers $B$, Schut $E$, van der Burg E, Braumuller TM, Egan DA, Holstege $H$, Edser P, Adams DJ, Wade-Martins R, Bouwman P, Jonkers J: A high-throughput pharmaceutical screen dentifies compounds with specific toxicity against BRCA2-deficient tumors. Clin Cancer Res 2010, 16:99-108.

30. Osher DJ, Kushner YB, Arseneau J, Foulkes WD: Melphalan as a treatment for BRCA-related ovarian carcinoma: can you teach an old drug new tricks? J Clin Pathol 2011, 64:924-926.

31. Fogelman DR, Wolff RA, Kopetz S, Javle M, Bradley C, Mok I, Cabanillas F, Abbruzzese JL: Evidence for the efficacy of Iniparib, a PARP-1 inhibitor, in BRCA2-associated pancreatic cancer. Anticancer Res 2011, 31:1417-1420.

32. Sonnenblick A, Kadouri L, Appelbaum L, Peretz T, Sagi M, Goldberg Y, Hubert A: Complete remission, in BRCA2 mutation carrier with metastatic pancreatic adenocarcinoma, treated with cisplatin based therapy. Cancer Biol Ther 2011, 12:165-168.

33. Villarroel MC, Rajeshkumar NV, Garrido-Laguna I, De Jesus-Acosta A, Jones S, Maitra A, Hruban RH, Eshleman JR, Klein A, Laheru D, Donehower R, Hidalgo $M$ : Personalizing cancer treatment in the age of global genomic analyses: PALB2 gene mutations and the response to DNA damaging agents in pancreatic cancer. Mol Cancer Ther 2011, 10:3-8.

34. Lowery MA, Kelsen DP, Stadler ZK, Yu KH, Janjigian YY, Ludwig E, D'Adamo DR, Salo-Mullen E, Robson ME, Allen PJ, Kurtz RC, O'Reilly EM: An emerging entity: pancreatic adenocarcinoma associated with a known BRCA mutation: clinical descriptors, treatment implications, and future directions. Oncologist 2011, 16:1397-1402.

35. Faluyi OO, Tran B, Kanji Z, Moore S, Zogopoulos G, Borgida A, Holter S, Gallinger S, Moore MJ: Benefits of platinum-based chemotherapy (Pt-chemo) in pancreatic adenocarcinoma (PC) associated with BRCA mutations: a translational case series. J Clin Oncol 2012, 30(Suppl):abstr 4058.

36. Vilar E, Gruber SB: Microsatellite instability in colorectal cancer-the stable evidence. Nat Rev Clin Oncol 2010, 7:153-162.

37. Sinicrope FA, Foster NR, Thibodeau SN, Marsoni S, Monges G, Labianca R, Kim GP, Yothers G, Allegra C, Moore MJ, Gallinger S, Sargent DJ: DNA mismatch repair status and colon cancer recurrence and survival in clinical trials of 5-fluorouracil-based adjuvant therapy. J Natl Cancer Inst 2011, 103:863-875

38. Smits EL, Ponsaerts P, Berneman ZN, Van Tendeloo VF: The use of TLR7 and TLR8 ligands for the enhancement of cancer immunotherapy. Oncologist 2008, 13:859-875.

39. Hodi FS, O'Day SJ, McDermott DF, Weber RW, Sosman JA, Haanen JB, Gonzalez R, Robert C, Schadendorf D, Hassel JC, Akerley W, van den Eertwegh AJ, Lutzky J, Lorigan P, Vaubel JM, Linette GP, Hogg D, Ottensmeier CH, Lebbé C, Peschel C, Quirt I, Clark JI, Wolchok JD, Weber JS, Tian J, Yellin MJ, Nichol GM, Hoos A, Urba WJ: Improved survival with ipilimumab in patients with metastatic melanoma. N Engl J Med 2010, 363:711-723.

40. Wells SA Jr, Gosnell JE, Gagel RF, Moley J, Pfister D, Sosa JA, Skinner M Krebs A, Vasselli J, Schlumberger M: Vandetanib for the treatment of patients with locally advanced or metastatic hereditary medullary thyroid cancer. J Clin Oncol 2010, 28:767-772.

41. Wells SA Jr, Robinson BG, Gagel RF, Dralle H, Fagin JA, Santoro M, Baudin E, Elisei R, Jarzab B, Vasselli JR, Read J, Langmuir P, Ryan AJ, Schlumberger MJ: Vandetanib in patients with locally advanced or metastatic medullary thyroid cancer: a randomized, double-blind phase III trial. J Clin Oncol 2012, 30:134-141.

42. Tang JY, Mackay-Wiggan JM, Aszterbaum M, Yauch RL, Lindgren J, Chang K, Coppola C, Chanana AM, Marji J, Bickers DR, Epstein EH Jr: Inhibiting the hedgehog pathway in patients with the basal-cell nevus syndrome. N Engl J Med 2012, 366:2180-2188.
43. Krueger DA, Care MM, Holland K, Agricola K, Tudor C, Mangeshkar P, Wilson KA, Byars A, Sahmoud T, Franz DN: Everolimus for subependymal giantcell astrocytomas in tuberous sclerosis. N Engl J Med 2010, 363:1801-1811.

44. O'Daniel JM, Lee K: Whole-genome and whole-exome sequencing in hereditary cancer: impact on genetic testing and counseling. Cancer $J$ 2012, 18:287-292.

doi:10.1186/1897-4287-11-2

Cite this article as: Imyanitov and Byrski: Systemic treatment for hereditary cancers: a 2012 update. Hereditary Cancer in Clinical Practice $201311: 2$.

\section{Submit your next manuscript to BioMed Central and take full advantage of:}

- Convenient online submission

- Thorough peer review

- No space constraints or color figure charges

- Immediate publication on acceptance

- Inclusion in PubMed, CAS, Scopus and Google Scholar

- Research which is freely available for redistribution 